\title{
An Economic Assessment of Selected Integration and Automation Technologies
}

\author{
Robert E. Chapman
}

\author{
Office of Applied Economics, Building and Fire Research Laboratory (BFRL) \\ National Institute of Standards and Technology (NIST), Gaithersburg, MD 20899 \\ robert.chapman@nist.gov
}

\begin{abstract}
This paper presents a critical analysis of the economic impacts of past, ongoing, and planned research of BFRL's construction systems integration and automation technologies (CONSIAT) program. The CONSIAT program is an interdisciplinary research effort within BFRL to develop key enabling technologies, standard communication protocols, and advanced measurement technologies needed to facilitate the delivery of fully-integrated and automated project process (FIAPP) products and services to the construction industry. BFRL is participating in a public-private partnership focused on early commercialization of FIAPP products and services. The results of this analysis demonstrate that the use of FIAPP products and services will generate substantial cost savings to the capital facilities industry. The present value of savings nationwide expected from the use of FIAPP products and services in capital facilities over the next 15 years exceeds $\$ 3.5$ billion. The present value of cost savings due to the publicprivate partnership's efforts focused on early commercialization of FIAPP products and services is expected to exceed $\$ 280$ million.
\end{abstract}

Keywords: Building economics; commercial buildings; construction; impact evaluation; industrial facilities

\section{INTRODUCTION:}

The capital facilities industry ${ }^{1}$ is facing several significant competitive challenges that will affect its future growth potential. Owners of capital facilities and contractors engaged in the construction of those facilities are pressing for reductions in delivery time as a means of improving their competitive positions. Owner concerns over both the first costs and the life-cycle costs of capital facilities and tightening profit margins for contractors are also affecting the competitive positions of each stakeholder. One means of improving the competitive position of each stakeholder in the capital facilities industry is through the development, adoption, and use of

\footnotetext{
1 The capital facilities industry covers constructionrelated activities and the associated supply chains throughout the life cycle of industrial facilities and commercial buildings. Industrial facilities include utilities, government facilities, and facilities where the manufacturing of products or commodities takes place. Commercial buildings include private- and publicsector office buildings, institutional buildings, and service businesses.
}

fully-integrated and automated project process (FIAPP) products and services.

FIAPP products and services offer the potential to reduce capital costs, reduce the delivery time of capital projects, and improve safety performance during construction. But investments in and the use of FIAPP products and services will be forthcoming only if the capital facilities industry perceives that the economic benefits outweigh the costs of using such products and services. Being able to demonstrate net economic savings from using FIAPP products and services will encourage their acceptance and use. The focus of this paper is on documenting how the use of FIAPP products and services in the capital facilities industry will generate significant net economic savings to the owners, operators, and managers of those facilities and to the contractors engaged in the construction of those facilities. These savings are based on results published in two economic impact assessments of BFRL's CONSIAT-related research and development effort $[1,2]$. 


\section{A CASE STUDY OF THE CAPITAL FACILITIES INDUSTRY:}

The case study is divided into two sections. The first section focuses on data and assumptions. The second analyzes the cost savings from FIAPP products and services in the capital facilities industry.

\subsection{Data and Assumptions}

The base year establishes the anchor point for all calculations. The base year for computing all FIAPP-related costs and savings is 1997, a year for which authoritative and comprehensive construction industry cost data are available.

The diffusion of FIAPP products and services into the capital facilities industry employs two sets of diffusion models: one set for industrial facilities and one set for commercial buildings. Each set employs a primary diffusion model. The primary diffusion model, $P_{\eta}(t)$, gives the proportion of potential users who employ FIAPP products and services in time period $t$, where $t=1$ corresponds to 2005 , the anticipated time of first commercial use. In each set of diffusion models, the subscript $\eta$ designates the market saturation level. The diffusion of FIAPP products and services into the marketplace is modeled up through 2017. By 2017, the use of FIAPP products and services is expected to be widespread. For more about the diffusion models, see $[1,2]$.

In order to estimate costs and savings due to the use of FIAPP products and services, it is necessary to specify both a base case and a FIAPP alternative. The term base case is used to represent the configuration that maintains the status quo (i.e., the "average" use of traditional design, information, and construction technologies). The FIAPP alternative is the configuration that provides equivalent or enhanced performance for all features of the base case through the use of FIAPP products and services.

There are two key differences between the two configurations. First, the degree to which construction activities (e.g., materials management) and facility service features (e.g., maintenance and repair procedures) are integrated, automated, and controlled is significantly higher in the FIAPP alternative. The second difference is that the FIAPP alternative has the potential to achieve enhanced performance for selected construction activities (e.g., better control of project cost and schedule) and facility service features (e.g., reduced maintenance and repair costs). These differences, although interrelated, are crucial in structuring differences in costs (e.g., due to the installation of additional equipment and software to generate improved systems integration, automation, and control) and savings (e.g., maintenance and repair cost savings due to the availability of electronic "as-built" information) between the two configurations.

The enhanced performance of the FIAPP alternative $v i s-\grave{a}$-vis the base case produces five types of cost savings. These cost savings are: (1) lower first costs; (2) lower maintenance and repair costs; (3) fewer construction-related accidents; (4) reductions in delivery time; and (5) higher net income for contractors. Lower first costs are registered through a reduction in a typical project's total installed costs (i.e., all project-related costs with the exception of land costs). Lower maintenance and repair costs are registered through reductions in future costs. Fewer construction-related accidents are registered through reductions in direct jobsite costs (e.g., medical costs), indirect jobsite costs (e.g., lost productivity of the crew due to the accident), and liability costs (e.g., claims costs). Reductions in delivery time are registered through increased opportunities for product sales and rental income. Higher net income for contractors is registered through the contractor's increased capability to control cost growth during the project delivery process. Cost savings accrue to owners and contractors in different ways. Lower first costs, lower maintenance and repair costs, and savings stemming from the earlier start-up of operations accrue to the owners and operators of capital facilities. Cost savings due to fewer constructionrelated accidents and higher net income accrue to contractors.

If capital facility owners, operators, and contractors employ the FIAPP alternative rather than the base case, they can expect to bear three types of additional costs. These costs are: (1) 
higher evaluation costs; (2) increased costs of adapting new building products and services to industry use; and (3) increased training costs. These three costs may be classified as newtechnology introduction costs. Ehlen and Marshall [3] define new-technology introduction costs as those costs covering the activities that bring the material/product from the research laboratory to full field implementation. New-technology introduction costs include the extra time and labor to design, test, monitor, and use the new technology. Ehlen's and Marshall's research on new-technology introduction costs is particularly relevant for this case study because they demonstrate that new-technology introduction costs disappear once the designer is satisfied with the technology's performance, the technology enters full implementation, and its application has become routine.

In performing the calculations presented in this case study, as well as those presented in [1, 2], a conservative approach to the estimation of savings and costs was employed. Potential cost savings are estimated based on project data from the Construction Industry Institute (CII) Benchmarking and Metrics Database. ${ }^{2}$ These data were provided to NIST by CII as part of a research collaboration on the use of design/information technologies [4]. Because these technologies are commercially available now, they do not include the full potential for savings expected from FIAPP products and services. Thus, the cost savings reported here are lower-bound estimates of the savings expected from the use of FIAPP products and services. On the other hand, new-technology introduction costs are held constant throughout the study period. Since these costs are expected to decline over time, the estimated values for net economic savings reported here are also lowerbound estimates.

\subsection{Analysis Results}

Three types of information were combined to generate an estimate of cost savings nationwide. These three types of information are related to: (1) the diffusion models; (2) the cost savings due to

\footnotetext{
${ }^{2}$ All data provided to NIST by CII have been aggregated in a manner that precludes identification of an individual company's or project's performance.
}

reductions in first costs, maintenance and repair costs, and construction-related accidents and the increases in net income for owners and contractors due to reductions in delivery time and higher contractor profit margins; and (3) new-technology introduction costs. Estimates are produced for each year from 2005 to 2017. Each year's net cost savings was then discounted to a present value and summed to get the present value of cost savings nationwide. All present value calculations are based on standardized practices [5].

Table 1 summarizes how cost savings by category and in total are calculated. The years for which cost savings are calculated are listed in Column 1 of Table 1. Annual values for each category of cost savings are recorded in Column 2 for first costs, Column 3 for maintenance and repair costs, Column 4 for reductions in delivery time, Column 5 for higher net income for contractors, and Column 6 for construction-related accidents avoided. Note that no cost savings for any category occur until 2005, the year in which FIAPP products and services are expected to first become commercially available.

Reference to Columns 2 through 6 of Table 1 reveals different rates of change for cost savings. Cost savings increase slowly at first and then increase rapidly during the middle years (e.g., 2009 through 2013). The middle years of the study period correspond to the greatest rate of penetration of FIAPP products and services into the market place. Market penetration is modeled through application of two sets of diffusion models. As the rate of penetration into the market place slows, cost savings level off. In the case of the maintenance and repair category (see Column 3), cost savings peak in 2014 and then decline. ${ }^{3}$ The differing rates of change have implications for net cost savings nationwide, which are presented in Table 2.

In addition to annual cost savings by category, Table 1 also contains total cost savings by year. These cost savings are recorded in Column 7 .

\footnotetext{
3 Reductions in maintenance and repair costs are measured on an annually recurring basis from the date of installation until the end of the study period in 2017 . Thus, installations in the early (e.g., 2005) and middle years (e.g., 2012) have more years to generate savings than those occurring at the end of the study period.
} 
Total cost savings for each year equal the sum of each category's cost savings for that year. Total cost savings, denominated in millions of 1997 dollars, increase steadily between 2005 and 2016.

Table 2 summarizes how the present values of net cost savings nationwide by year and in total are calculated. The table also includes information on total cost savings, additional FIAPP-related installation costs, net cost savings, and the discount factor needed to translate yearly net cost savings into yearly present value cost savings nationwide. The years for which present values are calculated are listed in Column 1 of Table 2. Column 2 contains total cost savings by year in millions of 1997 dollars. The total cost savings for each year is transferred from the respective row of Column 7 of Table 1. The new-technology introduction costs associated with investments in FIAPP products and services for each year are recorded in Column 3 of Table 2. The difference between total cost savings and new-technology introduction costs equals net cost savings. Column 4 records net cost savings for each year in millions of 1997 dollars. Note that net cost savings increase steadily until 2015 . The calculated value of the single present value factor for each year is recorded in Column 5. All entries are calculated using a real discount rate of $7 \%$. Because 1997 is the base year, the single present value factor takes on a value of 1.0 for that year. For years following 1997, the single present value factor is less than 1.0. The present value of net cost savings nationwide by year is recorded in Column 6 . It equals the product of the net cost savings, in Column 4, and the single present value factor, in Column 5, for that year. Note that the present value of net cost savings nationwide increases steadily until 2015 .

Because the entries in Column 6 are in present value terms, they can be summed to get total cost savings nationwide over the entire study period. Total cost savings nationwide resulting from the three sets of baseline analysis calculations are more than $\$ 3.5$ billion (\$3 532 million in present value 1997 dollars); see the bottom of Column 6 in Table 2.

Reference to Table 2 demonstrates the magnitude of the savings to the nation from using FIAPP products and services in the capital facilities industry. These cost savings nationwide also provide a basis for measuring the value of the public-private partnership's contribution. BFRL's dual role as a facilitator and developer of key FIAPP enabling technologies is expected to speed up the introduction of FIAPP products and services into the commercial marketplace. Because of the public-private partnership, FIAPP products and services are expected to be commercially available in 2005. Without a viable public-private partnership, the commercial introduction of FIAPP products and services is expected to be delayed until 2009. Information from subject matter experts and similar economic impact assessments suggest a range of values from two to five years for the likely delay. See $[1,2]$ to examine how variations in the likely delay were modeled.

Because the public-private partnership's efforts are expected to result in faster introduction of FIAPP products and services, those savings which would have been foregone in the event of a delay are attributable to the public-private partnership. Therefore, any savings over the first four years (starting with 2005), prior to the "delayed" introduction of FIAPP products and services in 2009, would have been foregone. Such an accounting framework may be handled through use of a 0 or 1 weighting factor. For those years in which savings are attributable to the public-private partnership, the weighting factor takes on a value of 1 . The present value of those four-year's worth of savings exceeds $\$ 280$ million, a strong indication of the value added of the collaborative efforts of the public-private partnership. ${ }^{4}$

\section{CONCLUSIONS:}

The \$3.5 billion magnitude of national cost savings is impressive. Does it indicate, however, that investment in FIAPP products and services by individual owners and contractors will be cost effective? The answer to that question is almost certainly yes. Consider the case of the earliest adopters of FIAPP products and services, those owners and contractors expected to invest in 2005. The aggregate investments, as measured by new-

\footnotetext{
${ }^{4}$ CONSIAT-related research and development costs by BFRL are not included in the results presented in this article. Readers interested in how these costs were used to estimate the return on the public sector's CONSIATrelated investment are referred to $[1,2]$.
} 
technology introduction costs, made by these owners/contractors is estimated as \$24.0 million (see column 3 of Table 2). Their total cost savings are estimated as $\$ 71.6$ million (see column 2 of Table 2). Thus, every dollar invested in 2005 generates nearly $\$ 3.00$ in return. However, this is an incomplete picture, since the savings and costs accruing to owners and contractors are not evenly distributed. A more complete picture is provided through reference to Table 1 . In Table 1, the different streams of cost savings are recorded according to whom they accrue. The owners of capital facilities capture the cost savings recorded in Columns 2, 3, and 4, whereas contractors capture the cost savings recorded in Columns 5 and 6. For early owner adopters, the entries in Columns 2 and 4 represent immediate, first-year cost savings of approximately $\$ 40.0$ million. Thus, the entire first year's investment (i.e., newtechnology introduction costs) can be covered by first-year cost savings captured by owners. Future owner cost savings due to reduced maintenance and repair expenditures add another $\$ 15.5$ million. Contractor cost savings are lower than owner cost savings, but part of these lower savings are due to the more stringent values of incidence rates associated with the CII safety data versus industry incidence rates in calculating improved safety performance. Thus, it is likely that even if contractors bear a larger share of new-technology introduction costs, they will find investment in FIAPP products and services to be highly cost effective. These savings, coupled with the likelihood that new-technology introduction costs will decline over time, indicate that FIAPP products and services are an emerging technology whose time has come.

\section{REFERENCES:}

1. Chapman, Robert E. 2000. Benefits and Costs of Research: A Case Study of Construction Systems Integration and Automation Technologies in Industrial Facilities. NISTIR 6501. Gaithersburg, MD: National Institute of Standards and Technology.

2. Chapman, Robert E. 2001. Benefits and Costs of Research: A Case Study of Construction Systems Integration and Automation Technologies in Commercial Buildings. NISTIR 6763. Gaithersburg, MD: National Institute of Standards and Technology.

3. Ehlen, Mark A., and Harold E. Marshall. 1996. The Economics of New-Technology Materials: A Case Study of FRP Bridge Decking. NISTIR 5864. Gaithersburg, MD: National Institute of Standards and Technology.

4. Thomas, Stephen R., Candace L. Macken, and Sang-Hoon Lee. 2001. Impacts of Design/Information Technology on Building and Industrial Projects. NIST GCR 01-828. Gaithersburg, MD: National Institute of Standards and Technology.

5. American Society for Testing and Materials (ASTM). Fourth Edition, 1999. ASTM Standards on Building Economics. West Conshohocken, PA: ASTM. 
Table 1. Cost Savings by Category and in Total by Year: 2005-2017

\begin{tabular}{|c|c|c|c|c|c|c|}
\hline \multirow{2}{*}{ Year } & \multicolumn{2}{|c|}{ Annual Cost Savings in Millions of 1997 Dollars by Category Dud } & \multicolumn{1}{c|}{ Total Cost Saving } \\
\cline { 2 - 5 } & $\begin{array}{c}\text { Reductions i } \\
\text { First Cost }\end{array}$ & $\begin{array}{c}\text { Reduced } \\
\text { M aintenanc } \\
\text { and Repair }\end{array}$ & $\begin{array}{c}\text { Reductions is } \\
\text { Delivery Tim }\end{array}$ & $\begin{array}{c}\text { Higher } \\
\text { Contractor } \\
\text { Net Income }\end{array}$ & $\begin{array}{c}\text { Improved } \\
\text { Safety } \\
\text { Performance }\end{array}$ & $\begin{array}{c}\text { Year in Million } \\
\text { of 1997 Dollars }\end{array}$ \\
\hline Col. (1) & Col. (2) & Col. (3) & Col. (4) & Col. (5) & Col. (6) & $\begin{array}{c}\text { Col. (7) } \\
\text { (2)+(3)+(4)+(5)+(6) }\end{array}$ \\
\hline 2005 & 20.6 & 15.5 & 19.7 & 15.1 & 0.7 & 71.6 \\
2006 & 49.9 & 29.6 & 47.2 & 36.7 & 1.6 & 165.0 \\
2007 & 79.9 & 40.5 & 74.5 & 58.7 & 2.4 & 256.0 \\
2008 & 125.5 & 62.7 & 115.6 & 92.2 & 3.6 & 399.7 \\
2009 & 192.1 & 94.5 & 174.7 & 141.1 & 5.2 & 607.6 \\
2010 & 283.2 & 137.1 & 254.3 & 208.1 & 7.3 & 890.1 \\
2011 & 397.6 & 189.6 & 352.6 & 292.1 & 9.7 & 1241.7 \\
2012 & 526.5 & 247.1 & 461.3 & 386.8 & 12.2 & 1634.0 \\
2013 & 655.5 & 299.3 & 567.4 & 481.6 & 14.4 & 2018.2 \\
2014 & 769.9 & 330.9 & 658.5 & 565.6 & 16.0 & 2340.8 \\
2015 & 861.0 & 323.1 & 727.7 & 632.5 & 17.0 & 2561.3 \\
2016 & 927.5 & 261.3 & 774.9 & 681.4 & 17.3 & 2662.5 \\
2017 & 973.2 & 146.8 & 803.6 & 715.0 & 17.2 & 2655.8 \\
\hline
\end{tabular}

Table 2. Present Value Cost Savings Nationwide by Year and in Total

\begin{tabular}{|c|c|c|c|c|c|}
\hline Year & $\begin{array}{c}\text { Total Cost } \\
\text { Savings in } \\
\text { Millions }\end{array}$ & $\begin{array}{c}\text { New- } \\
\text { Technology } \\
\text { Introduction } \\
\text { Costs }\end{array}$ & $\begin{array}{c}\text { Net Cost } \\
\text { Savings in } \\
\text { Millions by } \\
\text { Year }\end{array}$ & $\begin{array}{c}\text { Single Present } \\
\text { Value Factor by } \\
\text { Year }\end{array}$ & $\begin{array}{c}\text { Present Value of } \\
\text { Net Cost Savings } \\
\text { Nationwide by } \\
\text { Year in Millions }\end{array}$ \\
\hline Col. (1) & Col. (2) & Col. (3) & $\begin{array}{c}\text { Col. (4) } \\
\text { (2) - (3) }\end{array}$ & Col. (5) & $\begin{array}{c}\text { Col. (6) } \\
\text { (4) x (5) }\end{array}$ \\
\hline 2005 & 71.6 & 24.0 & 47.6 & 0.582 & 27.7 \\
2006 & 165.0 & 58.3 & 106.7 & 0.544 & 58.0 \\
2007 & 256.0 & 93.3 & 162.7 & 0.508 & 82.7 \\
2008 & 399.7 & 146.6 & 253.1 & 0.475 & 120.2 \\
2009 & 607.6 & 224.4 & 383.3 & 0.444 & 170.2 \\
2010 & 890.1 & 330.8 & 559.3 & 0.415 & 232.1 \\
2011 & 1241.7 & 464.4 & 777.3 & 0.388 & 301.5 \\
2012 & 1634.0 & 615.0 & 1019.0 & 0.362 & 369.3 \\
2013 & 2018.2 & 765.6 & 1252.6 & 0.339 & 424.3 \\
2014 & 2340.8 & 899.2 & 1441.7 & 0.317 & 456.4 \\
2015 & 2561.3 & 1005.6 & 1555.7 & 0.296 & 460.3 \\
2016 & 2662.5 & 1083.4 & 1579.1 & 0.277 & 436.6 \\
2017 & 2655.8 & 1136.7 & 1519.1 & 0.258 & 392.6 \\
\hline & & & & & \\
& & &
\end{tabular}

